\title{
The implications of hypersomnia in the context of major depression: Results from a large, international, observational study
}

\author{
A. Murru ${ }^{a}$, G. Guiso ${ }^{a, b}$, M. Barbuti ${ }^{c}$, G. Anmella ${ }^{a}$, \\ N. Verdolini ${ }^{a, d, e}$, L. Samalin ${ }^{a, f, g}$, J.M. Azorin's, J. Jules Angst ${ }^{h}$, \\ C.L. Bowden ${ }^{i}$, S. Mosolov ${ }^{j}$, A.H. Young ${ }^{k}$, D. Popovic ${ }^{a, l}$, \\ M. Valdes ${ }^{m}$, G. Perugi ${ }^{c}$, E. Vieta ${ }^{a, *}$, I. Pacchiarotti ${ }^{a}$, For the \\ BRIDGE-II-Mix Study Group
}

${ }^{a}$ Barcelona Bipolar and Depressive Disorders Unit, Institute of Neuroscience, Hospital Clinic, University of Barcelona, IDIBAPS, CIBERSAM, Barcelona, Catalonia, Spain

${ }^{\mathrm{b}}$ Clinica Psichiatrica, Dipartimento di Igiene e Sanità, Università di Cagliari, Italy

'Division of Psychiatry, Clinical Psychology and Rehabilitation, Department of Medicine, University of Perugia, Santa Maria della Misericordia Hospital, Edificio Ellisse, 8 Piano, Sant'Andrea delle Fratte, 06132, Perugia, Italy

${ }^{\text {d}}$ FIDMAG Germanes Hospitalàries Research Foundation, Sant Boi de Llobregat, Barcelona, Catalonia, Spain

e Division of Psychiatry, Clinical Psychology and Rehabilitation, Department of Medicine, Santa Maria della Misericordia Hospital, University of Perugia, Perugia, Italy

${ }^{f} \mathrm{CHU}$ Clermont-Ferrand, Department of Psychiatry, University of Auvergne, Clermont-Ferrand, France

'Fondation FondaMental, Hôpital Albert Chenevier, Pôle de Psychiatrie, Créteil, France

h Department of Psychiatry, Psychotherapy and Psychosomatics, Psychiatric Hospital, University of

Zurich, Zurich, Switzerland

iUniversity of Texas Health Science Center, San Antonio, USA

${ }^{\mathrm{M}}$ Moscow Research Institute of Psychiatry, Russia

${ }^{k}$ Centre for Affective Disorders, Department of Psychological Medicine, Institute of Psychiatry,

Psychology \& Neuroscience, King's College London, London, UK

'Psychiatry B, Sheba Medical Center, Israel

m Department of Medicine, Sleep Unit, Hospital Clínic, University of Barcelona, IDIBAPS, CIBERSAM;

Barcelona, Catalonia, Spain

Received 30 October 2018; received in revised form 31 January 2019; accepted 14 February 2019

Available online $x x x$

\footnotetext{
* Corresponding author.

E-mail address: EVIETA@clinic.cat (E. Vieta).
} 


\section{KEYWORDS}

Major depression; Bipolar depression; Mixed features; Hypersomnia; Comorbidity; Screening

\begin{abstract}
According to the DSM-5, "reduction in the need for sleep" is the only sleep-related criteria for mixed features in depressive episodes. We aimed at studying the prevalence, clinical correlates and the role of hypersomnia in a sample of acutely depressed patients. Secondarily, we factors significantly increasing the odds of hypersomnia were studied. We conducted a posthoc analysis of the BRIDGE-II-Mix study. Variables were compared between patients with hypersomnia (SLEEP+) and with insomnia (SLEEP-) with standard bivariate tests. A stepwise backward logistic regression model was performed with SLEEP+ as dependent variable. A total of 2514 subjects were dichotomized into SLEEP $+(n=423,16.8 \%)$ and SLEEP $-(n=2091,83.2 \%)$. SLEEP + had significant higher rates of obese BMI $(p<0.001)$, BD diagnosis $(p=0.027)$, severe $\operatorname{BD}(p<0.001)$, lifetime suicide attempts $(p<0.001)$, lower age at first depression $(p=0.004)$ than SLEEP-. Also, SLEEP+ had significantly poorer response to antidepressants (AD) such as (hypo)manic switches, $A D$ resistance, affective lability, or irritability (all $0<0.005)$. Moreover, SLEEP + had significantly higher rates of mixed-state specifiers than SLEEP- (all $0<0.006$ ). A significant contribution to hypersomnia in our regression model was driven by metabolic-related features, such as "current bulimia" $(O R=4.21)$ and "overweight/obese BMI $(O R=1.42)$ ". Globally, hypersomnia is associated with poor outcome in acute depression. Hypersomnia is strongly associated with mixed features and bipolarity. Metabolic aspects could influence the expression of hypersomnia, worsening the overall clinical outcome. Along with commonly used screening tools, detection of hypersomnia has potential, costless discriminative validity in the differential diagnosis unipolar and bipolar depression.

(C) 2019 Elsevier B.V. and ECNP. All rights reserved.
\end{abstract}

\section{Introduction}

Sleep disturbances are highly prevalent in affective disorders (Asaad et al., 2016; Bradley et al., 2017). In bipolar disorder (BD) they may occur in $30-60 \%$ of patients, but reported rates vary from $10 \%$ to $80 \%$ depending on definition and management of potential confounding factors such as pharmacological treatments (Steinan et al., 2016a; 2016b). Sleep disturbances have been increasingly recognized as important predictors of relapse in both major depressive disorder (MDD) and BD (Bao et al., 2017; Bromberger et al., 2016; Craig et al., 2000; Gershon et al., 2017; Sakurai et al., 2017). Most descriptive studies on depressed or BD subjects with sleep alterations have focused on insomnia or decreased need to sleep, while fewer studies explored the presence of hypersomnia and its associated clinical features, despite its reported prevalence in $17-78 \%$ of patients with BD depression (Steinan et al., 2016b).

Recent data on theoretical models of BD supported the hypothesis that sleep disturbances may be a marker of underlying global circadian dysregulation (Kapczinski et al., 2011; Rosa et al., 2013), including unfavorable rapid cycling course or mood instability (Mosolov, 1996; Strejilevich et al., 2013) and involving other parameters like the body mass index (BMI) (Samalin et al., 2017; Steinan et al., 2016a). Specifically, a Delayed Sleep Phase (DSP), defined as sleep onset insomnia and/or morning sleepiness that may extend for 3-6 h, was present in $10 \%$ of a sample of 404 BD patients and associated to a higher mean BMI (Steinan et al., 2016b). In a cross-sectional study higher BMI in BD but not healthy controls significantly correlated with lower sleep efficiency, shorter total sleep time, longer sleep onset latency, higher fragmentation index, higher inter-day variability (Boudebesse et al., 2015).

A relationship between depression, especially with atypical features, and obesity has been widely demonstrated (Chou and Yu, 2013; de Wit et al., 2010; Lasserre et al., 2014; Luppino et al., 2010) but the nature of this association still remains unclear. Atypical symptoms, which include hypersomnia, in depressed patients have been associated with both obesity and bipolarity (Forty et al., 2008; Łojko et al., 2015). Likewise, excess bodyweight and obesity are highly prevalent in individuals with BD and this association is considered as one of many comorbidities generating concern in BD populations due to important health implications (Liu et al., 2013). Unfortunately, the direction of this association is not clear. In fact, obese patients show a higher risk of developing major MDD and BD (Simon et al., 2006), but the course of bipolar depression is also frequently affected by the development of overweigh and obesity, possibly related to the effects of psychotropic medications or to comorbid diagnoses with eating disorders, such as binge eating disorder (BED). Notwithstanding, this association underpins genetic and neurobiological liability (McElroy et al., 2018, 2013, 2011; McElroy and Keck, 2014). In BD, obesity is directly associated with a worse illness course and outcome, including increased suicidality and decreased cognitive performance (Fagiolini et al., 2004; Yim et al., 2012). Metabolic comorbidity in BD may also act as a "mood destabilizer", increasing depressive symptom severity and recurrence (Liu et al., 2013). A recent post-hoc analysis of the Bipolar Disorders: Improving Diagnosis, Guidance and Education (BRIDGEII-MIX) naturalistic study (Perugi et al., 2016; 2015; Popovic et al., 2015) assessed the association between obesity and 
the presence of bipolar features, concluding that higher $\mathrm{BMI}$ in patients with major depression (MDE) seems to be associated with a lifetime diagnosis of $\mathrm{BD}$ and with a poorer illness outcome and suggesting that obesity in patients with MDE could be considered a possible marker of bipolarity (Petri et al., 2017).

The objective of the present post-hoc analysis was to assess possible diagnostic and clinical correlates of insomnia (SLEEP-) or hypersomnia (SLEEP+) in the population recruited for the BRIDGE-II-Mix study. Secondarily, a statistical model predicting the likelihood of hypersomnia was performed, as well as a statistical model to understand whether the presence of combined hypersomnia and overweight/obesity phenotype could define a subgroup of patients with specific clinical features.

\section{Methods}

\subsection{Study population recruitment}

This study is a post-hoc analysis of the BRIDGE-II-Mix study (Perugi et al., 2015). The primary objective of BRIDGE-II-MIX naturalistic study was to provide a reliable estimate of the frequency of mixed states in a large international sample of patients diagnosed with MDE according to several sets of criteria. The BRIDGE-II-Mix Study was a multisite, international, non-interventional, cross-sectional study. The recruitment procedure and the inclusion criteria have been described in a previous study (Popovic et al., 2015). From an initial pool of 2811 patients with MDE, sleep disturbances were detected in 2514 patients who were thus included in the present posthoc analysis.

\subsection{Data collection}

In a single consultation the participating psychiatrists completed a case report form for each patient, incorporating inclusion criteria, socio-demographic variables (age, gender and marital status), biometrics values (height and weight), in- or out-patient status, history of psychiatric symptoms (mood symptoms, suicide attempts) and previous psychiatric hospitalizations. Features of the MDE, including bipolar symptoms listed in the DSM-IV-TR diagnostic criteria for $B D$, known risk factors for BD (e.g. family history of BD, early onset depression), previous response to $A D s$, psychiatric comorbidity, current treatment and functional status determined by the investigator using the Global Assessment of Functioning (GAF) were assessed (Endicott et al., 1976).

The evaluation packet was explicitly structured to use skills that fully trained psychiatrists would have and routinely apply in conducting an initial evaluation of an acutely ill patient. No rating scales requiring calibration with a standard were incorporated. Raters were instructed to follow their usual practice, as training might have altered these practices and might be seen as a biasing factor.

The primary objective of the BRIDGE-II-MIX study was to establish the frequency of depressive mixed states by analyzing all the relevant symptoms of either pole. After the publication of DSM-5, this was post-hoc defined as (1) the proportion of patients fulfilling DSM- 5 criteria for MDE with mixed features (American Psychiatric Association, 2013), and (2) research based diagnostic criteria for mixed states (RDC). RDC are defined by the presence of MDE plus 3 out of the following 14 hypomanic symptoms for at least a week: irritable mood, affective lability, distractibility, psychomotor agitation, impulsivity, aggression (verbal or physical), racing thoughts, more talkative/pressure to keep talking, hyperactivity, increased energy, risky behavior, grandiosity, elation, hyper-sexuality. The proportion of patients fulfilling criteria for BD according to the DSMIV-TR and bipolarity specifier proposed by Angst et al. (2005; 2011; 2013) was also identified. The bipolarity specifier attributes a diagnosis of BD to patients who experienced an episode of elevated mood or irritable mood or increased activity with at least three of the symptoms listed under Criterion B of the DSM-IV-TR, associated with at least one of the three following consequences: (i) unequivocal and observable change in functioning uncharacteristic of the person's usual behavior, (ii) marked impairment in social or occupational functioning observable by others or (iii) requiring hospitalization or outpatient treatment. No minimum duration was required and no exclusion criteria were applied.

\subsection{Ethical aspects}

In each participating country, the study protocol was approved by the local ethics committee, in accordance with the Declaration of Helsinki. Each patient provided written informed consent in order to participate.

\subsection{Statistical analyses}

The sample was dichotomized into patients reporting reduced sleep (SLEEP-) and increased sleep (SLEEP+). Variables were compared between the 2 study subgroups with Chi-square (categorical variables) and Student's $t$-test (continuous variables). A stepwise backward logistic regression model was then used to identify the likelihood of selected variables in predicting insomnia versus hypersomnia. The stepwise modeling procedure started with the full model and consisted, for each step, in eliminating the least statistically significant variable from the model and re-computing the revised model, until all remaining variables were at $p<0.1$. Statistical analyses were performed using the Statistical Package for Social Sciences (Statistical Package for Social Science-SPSS, 23.0 version for Windows Inc., Chicago, IL, USA). All $p$ values were two-tailed and statistical significance was set at $p<0.05$.

\section{Results}

A total of 2514 depressed individuals were derived from the original BRIDGE-II-MIX sample and considered in the present post-hoc analysis. The sample was dichotomized into SLEEP - $(n=2091,83.2 \%)$ and SLEEP $+(n=423,16.8 \%)$ subgroups, based on the presentation of objective reduction of sleep or hypersomnia respectively.

When considering sociodemographic and lifestyle characteristics of the sample, SLEEP+ patients showed significant higher rates of single marital status $(29.3 \%$ vs. $22.9 \%$, $p=0.006)$ and obese BMI (23.0\% vs. $15.4 \%, p<0.001)$, significant less normal BMI (47.1\% vs. $37.1 \%, p<0.001)$ than SLEEP-. No differences were found in sex distribution or age at evaluation (see Table 1).

When considering characteristics related to current diagnosis and possible past course of illness, SLEEP+ subgroup showed significant higher rates of BD diagnosis $(20.6 \%$ vs. $16.0 \%, p=0.027)$, a more severe course of BD illness measured with $\mathrm{CGI}(2.80 \pm 1.72$ vs. $2.26 \pm 1.68$, $p<0.001)$, higher rates of atypical features $(32.2 \%$ vs. $1.8 \%, p<0.001)$ and lifetime suicide attempts $(29.3 \%$ vs. $21.0 \%, p<0.001)$, significant lower rates of MDD $(79.4 \%$ vs. 
Table 1 Sociodemographic and lifestyle characteristics of the included sample $(n=2514)$.

\begin{tabular}{|c|c|c|c|c|c|c|}
\hline \multirow[b]{2}{*}{ Variables (YES) } & \multicolumn{2}{|c|}{ Sleep- $(n=2091)$} & \multicolumn{2}{|c|}{ Sleep $+(n=423)$} & \multirow[b]{2}{*}{$\chi^{2}$} & \multirow[b]{2}{*}{$p$} \\
\hline & $n$ & $\%$ & $n$ & $\%$ & & \\
\hline Sex (female) & 1430 & 68.4 & 305 & 72.1 & 2.271 & 0.132 \\
\hline \multicolumn{7}{|l|}{ Marital status } \\
\hline Married & 1153 & 55.1 & 220 & 52.0 & 1.392 & 0.238 \\
\hline Divorced & 336 & 16.1 & 63 & 14.9 & 0.364 & 0.546 \\
\hline Single & 479 & 22.9 & 124 & 29.3 & 7.891 & 0.006 \\
\hline Current smoker & 725 & 34.7 & 158 & 37.4 & 1.109 & 0.292 \\
\hline \multicolumn{7}{|l|}{ BMI } \\
\hline Underweight & 77 & 3.8 & 22 & 5.3 & 2.145 & 0.143 \\
\hline Normal & 961 & 47.1 & 155 & 37.1 & 12.369 & $<0.001$ \\
\hline Overweight & 688 & 33.7 & 145 & 34.7 & 0.301 & 0.610 \\
\hline Obese & 314 & 15.4 & 96 & 23.0 & 15.197 & $<0.001$ \\
\hline Variable & Mean & SD & Mean & SD & $F$ & $p$ \\
\hline Age & 43.96 & 13.80 & 41.08 & 13.03 & 3.953 & $<0.001$ \\
\hline
\end{tabular}

Notes: BMI = Body Mass Index, underweight (<18.5), normal (18.5-25), Overweight (25-30), Obese (>30). SD = Standard Deviation.

84.0, $p<0.001)$, also at first episode $(18.0 \%$ vs. 26.0 , $p=0.027)$ than SLEEP-. SLEEP+ also showed significant lower age at first psychiatric symptoms $(29.14 \pm 12.19 \mathrm{vs}$. $33.38 \pm 12.93, p=0.012)$ and age at first depression onset $(32.55 \pm 11.75$ vs. $35.93 \pm 12.68, p=0.004)$ than SLEEP-. When considering past episodes, SLEEP+ patients showed a significantly higher number of depressions $(5.71 \pm 6.99$ vs. $4.48 \pm 5.78, p<0.001)$ and suicide attempts $(1.52 \pm 3.01$ vs. $0.41 \pm 3.98, p=0.031)$, last year's overall number of mood episodes $(2.99 \pm 6.66 \mathrm{vs}$. $2.12 \pm 3.94, p<0.001)$, total days spent depressed $(120.00 \pm 96.00$ vs. $107.94 \pm 96.14, p=0.016)$ and total days spent (hypo)manic 20.21 \pm 43.57 vs. $12.24 \pm 39.94$, $p<0.001$ ) than SLEEP - patients (see Table 2).

SLEEP + patients presented significantly higher rates of mixed-state according to RDC (32.9\% vs. $27.6 \%, p=0.029)$, but not to DSM-5 specifier $(5.0 \%$ vs. $8.3 \%, p=0.021)$. When considering each RDC mixed symptom, SLEEP+ presented more frequently racing thoughts, $(15.1 \%$ vs. $10.6 \%$, $p=0.007)$, affective lability (37.6\% vs. $27.5 \%, p<0.001)$, distractibility $(29.6 \%$ vs. $23.4 \%, p=0.007)$, impulsivity (16.8\% vs. $13.2 \%, p=0.048)$, hypersexuality (4.0\% vs. $2.3 \%$, $p=0.042$ ) than SLEEP-, and significantly less risky behavior (5.0\% vs. $7.8 \%, p=0.041)$.

Past treatments with antidepressants (AD) were statistically more frequent in SLEEP+ patients $(85.3 \%$ vs. $79.5 \%$, $p=0.006)$, and this subgroup of patients also presented significant higher rates in all variables related to poor response to $A D$, such as reporting (hypo)manic switches $(24.1 \%$ vs. $15.3 \%, p<0.001)$, resistance to $A D$ treatment $(34.3 \%$ vs. $27.1 \%, p=0.003)$, affective lability $(41.6 \%$ vs. $26.7 \%$, $p=0.001)$ or irritability $(33.1 \%$ vs. $24.8 \%, p<0.001)$ (see Table 3).

SLEEP+ patients presented frequent comorbidities with other psychiatric conditions, statistically significant compared to SLEEP- for obsessive-compulsive disorder (OCD, $7.6 \%$ vs. $4.2 \%, p=0.002)$, social phobia $(13.5 \%$ vs. $6.4 \%$, $p<0.001)$, generalized anxiety disorder (GAD, 23.2\% vs. $17.2 \%, p=0.003)$, binge eating syndrome $(13.7 \%$ vs. $6.0 \%$, $p<0.001)$, bulimia $(6.1 \%$ vs. $1.0 \%, p<0.001)$, night eating syndrome $(5.5 \%$ vs. $2.2 \%, p<=0.001)$. Atypical antipsy- chotics $(34.0 \%$ vs. $22.1 \%, p<0.001)$ and mood stabilizers $(40.0 \%$ vs. $26.0, p<0.001)$ were significantly more frequently used in SLEEP+ group (see Table 4).

Stepwise backward logistic regression was performed to assess the impact of 25 factors on the likelihood that patients would report a problem of hypersomnia.

The full model as a whole was significant, $\chi^{2}$ (12, $N=2461)=153.392, p<0.001$. A total of 11 independent variables made a unique statistically significant contribution to the model, here presented in order of strength in predicting hypersomnia: "current bulimia" (OR = 4.21), "current social phobia" $(\mathrm{OR}=1.77)$, "overweight/obese BMI $(O R=1.42)$ ", "affective lability with previous AD treatment" $(O R=1.37)$, "affective lability" $(O R=1.37)$, "treatment with atypical antipsychotics $(O R=1.36)$, "treatment with mood stabilizers" $(O R=1.33)$, "lifetime suicide attempts $(O R=1.31)$, "number of days depressed in the last year" $(O R=1.00)$, "age at first depression" $(O R=0.98)$ "risky behavior symptoms" (OR $=0.32$ ) (see Table 5).

We decided to consider dichotomized BMls subgroups, by dividing the sample in "patients with BMI above normal and "patients with BMI of normal value or below". Sleep subgroups still differed statistically, as SLEEP+ (241, 57.0\%) were more frequently overweight/obese than SLEEP- $(1002,47.9 \%, \chi 211.539, p=0.001)$. Given the consistent contribution of metabolic-related variables in predicting the model of hypersomnia, we conducted a secondary analysis on the patients with both hypersomnia and BMI above normal in order to define this more extreme, "atypical" phenotype. These patients presented themselves as a more extreme phenotype with respect to the SLEEP+ subgroup (see Supplementary Material Table S1). A similar comparison between this atypical profile and the opposite phenotype (sleep reduction/BMI below normal) showed again the clinical distance between these clinical phenotypes (see Supplementary Material Table S2). The stepwise backward logistic regression conducted on the extreme phenotype was also overall significant $(7, N=2478$, $\left.\chi^{2}=98.868, p<0.0005\right)$, with significant contribution made by current bulimia $(O R=3.99)$, current binge eating $(O R=2.30)$, current social phobia $(O R=1.65)$, current 
Table 2 Diagnostic and past course of illness characteristics of the included sample.

\begin{tabular}{|c|c|c|c|c|c|c|}
\hline \multirow[b]{2}{*}{ Variables (YES) } & \multicolumn{2}{|c|}{ Sleep $-(n=2091)$} & \multicolumn{2}{|c|}{ Sleep $+(n=423)$} & \multirow[b]{2}{*}{$\chi^{2}$} & \multirow[b]{2}{*}{$p$} \\
\hline & $n$ & $\%$ & $n$ & $\%$ & & \\
\hline \multicolumn{7}{|l|}{ Diagnosis } \\
\hline \multicolumn{7}{|l|}{ BD Diagnosis } \\
\hline Total & 334 & 16.0 & 87 & 20.6 & 5.326 & 0.027 \\
\hline BD type I & 206 & 9.9 & 54 & 12.8 & 3.222 & 0.080 \\
\hline BD type II & 128 & 6.1 & 33 & 7.8 & 1.657 & 0.198 \\
\hline UMD & 1757 & 84.0 & 336 & 79.4 & 5.326 & 0.027 \\
\hline First Episode & 543 & 26.0 & 76 & 18.0 & 12.137 & $<0.001$ \\
\hline \multicolumn{7}{|l|}{ Clinical features } \\
\hline Presence of fatigue/energy loss & 1960 & 93.9 & 412 & 97.4 & 8.381 & 0.004 \\
\hline Atypical features & 37 & 1.8 & 136 & 32.2 & 506.803 & $<0.001$ \\
\hline Lifetime suicide & 439 & 21.0 & 124 & 29.3 & 14.012 & $<0.001$ \\
\hline Illness onset & Mean & SD & Mean & SD & $\boldsymbol{F}$ & $p$ \\
\hline Age at 1st symptoms & 33.38 & 12.93 & 29.14 & 12.19 & 6.192 & $<0.001$ \\
\hline Age at 1 st depression & 35.93 & 12.68 & 32.55 & 11.75 & 5.041 & $<0.001$ \\
\hline \multicolumn{7}{|l|}{ Current episode } \\
\hline Duration & 93.43 & 123.85 & 98.01 & 139.85 & 0.457 & 0.499 \\
\hline Duration of (hypo)manic symptoms & 12.19 & 46.59 & 11.15 & 22.63 & 0.073 & 0.788 \\
\hline $\mathrm{N}$ of (hypo)manic symptoms & 1.80 & 2.69 & 2.08 & 2.75 & 3.72 & 0.054 \\
\hline Severity of mania & 1.32 & 0.82 & 1.32 & 0.84 & 2.082 & 0.149 \\
\hline Severity of depression & 4.50 & 0.98 & 4.53 & 0.89 & 0.208 & 0.648 \\
\hline Severity of BD & 2.26 & 1.68 & 2.80 & 1.72 & 33.140 & $<0.001$ \\
\hline \multicolumn{7}{|l|}{ Past episodes } \\
\hline $\mathrm{N}$ of depressions & 4.48 & 5.78 & 5.71 & 6.99 & 14.607 & $<0.001$ \\
\hline Tot suicidal attempts & 0.41 & 1.54 & 0.58 & 1.21 & 4.676 & 0.031 \\
\hline Tot hospitalizations & 1.72 & 3.98 & 1.52 & 3.01 & 0.962 & 0.327 \\
\hline \multicolumn{7}{|l|}{ Past year } \\
\hline $\mathrm{N}$ of mood episodes & 2.12 & 3.94 & 2.99 & 6.66 & 13.130 & $<0.001$ \\
\hline Tot days depressed & 107.94 & 96.14 & 120 & 96.00 & 5.854 & 0.016 \\
\hline Tot days (hypo)manic & 12.24 & 39.94 & 20.21 & 43.57 & 13.573 & $<0.001$ \\
\hline
\end{tabular}

Notes: BD = Bipolar Disorder; UMD = Unipolar Major Depression; $\mathbf{N}=$ Number; Tot = Total; SD = Standard Deviation.

treatment with mood stabilizers $(O R=1.50)$, current treatment with atypical antipsychotics $(O R=1.48)$, affective lability with previous $A D$ treatments $(O R=1.44)$, current affective lability $(O R=1.38)$ (see Supplementary Material Table S2).

\section{Discussion}

In the present post-hoc analysis on a large sample of acutely depressed patients recruited from a large multi-site study, hypersomnia showed a strong association with mixed features.

Sleep alterations in depression positively relate to a worse course of illness (Takaesu et al., 2017) and an increase in suicidality (Littlewood et al., 2018). More, sleep alterations are amongst the top warning signs of suicide (Bernert et al., 2017a; 2017b). While insomnia symptoms have been commonly described in mood disorders and $B D$, hypersomnia is a significant but underexplored problem (Vieta et al., 2018a; 2018b). Recently, a positive association between hypersomnia and suicidal behaviors has been reported (Michaels et al., 2017). In our sample of depressed subjects, as expected, sleep disturbances were mostly prevalent ( $N=2514$ of $2811,89,4 \%$ ). Among them, 83.2\% presented insomnia during the index episode SLEEP-, while $16.8 \%$ was experiencing hypersomnia SLEEP+. SLEEPpatients were more frequently at their first affective onset or were diagnosed with unipolar depression, compared with SLEEP+. Similar findings of high rates of insomnia have been found in major unipolar depression (approximately $90 \%$ ), indicative of initial diagnosis of depression and higher severity of symptoms (Baglioni and Riemann, 2012). On the contrary, a diagnosis of $\mathrm{BD}$ was significantly more frequent in the SLEEP+ group, supporting previous data on the frequent occurrence of atypical features in bipolar depression, previously described especially in BD type II (Thase, 2007). Notably, in our sample we did not find differences in BD subtypes among the SLEEP+ patients, in line with recent finding pointing on the prevalence of hypersomnia in BD type I (Kaplan and Williams, 2017). According to the primary aim of the study, we focused on the SLEEP+ subgroup and we found an overall higher severity of BD, higher number of mood episodes, depressions, and higher numbers of days spent depressed and/or (hypo)manic compared with the SLEEP - group. The last finding is an unexpected result since hypersomnia is not contemplated as a manic or hypomanic symptom (American Psychiatric Association, 2013). 
Table 3 Mixed specifiers and BD-related characteristics of the included sample.

\begin{tabular}{|c|c|c|c|c|c|c|}
\hline \multirow[b]{2}{*}{ Variables (YES) } & \multicolumn{2}{|c|}{ Sleep- $(n=2091)$} & \multicolumn{2}{|c|}{ Sleep $+(n=423)$} & \multirow[b]{2}{*}{$\chi^{2}$} & \multirow[b]{2}{*}{$p$} \\
\hline & $n$ & $\%$ & $n$ & $\%$ & & \\
\hline DSM-5 mixed specifier & 173 & 8.3 & 21 & 5.0 & 5.410 & 0.021 \\
\hline RDC mixed specifier & 577 & 27.6 & 139 & 32.9 & 4.790 & 0.029 \\
\hline \multicolumn{7}{|l|}{ RDC mixed symptoms } \\
\hline Psychomotor agitation & 342 & 16.4 & 58 & 13.7 & 1.839 & 0.175 \\
\hline Irritable mood & 667 & 31.9 & 151 & 35.7 & 2.313 & 0.128 \\
\hline Racing thoughts & 221 & 10.6 & 64 & 15.1 & 7.281 & 0.007 \\
\hline Affective lability & 576 & 27.5 & 159 & 37.6 & 17.149 & $<0.001$ \\
\hline More talkative/pressure to keep talking & 236 & 11.3 & 52 & 12.3 & 0.351 & 0.553 \\
\hline Distractibility & 489 & 23.4 & 125 & 29.6 & 7.244 & 0.007 \\
\hline Increased energy & 139 & 6.6 & 27 & 6.4 & 0.040 & 0.842 \\
\hline Aggression (verbal or physical) & 286 & 13.7 & 62 & 14.7 & 0.283 & 0.595 \\
\hline Hyperactivity & 168 & 8.0 & 34 & 8.0 & 0.000 & 0.998 \\
\hline Grandiosity & 69 & 3.3 & 19 & 4.5 & 1.480 & 0.224 \\
\hline Mood elation & 91 & 4.4 & 20 & 4.7 & 0.118 & 0.731 \\
\hline Impulsivity & 275 & 13.2 & 71 & 16.8 & 3.913 & 0.048 \\
\hline Risky behavior & 163 & 7.8 & 21 & 5.0 & 4.156 & 0.041 \\
\hline Hypersexuality & 48 & 2.3 & 17 & 4.0 & 4.149 & 0.042 \\
\hline \multicolumn{7}{|l|}{ Past treatments with ADs } \\
\hline Past use of ADs & 1662 & 79.5 & 361 & 85.3 & 7.685 & 0.006 \\
\hline (Hypo)manic switches & 319 & 15.3 & 102 & 24.1 & 19.799 & $<0.001$ \\
\hline Resistance to treatment & 566 & 27.1 & 145 & 34.3 & 9.018 & 0.003 \\
\hline Mood lability & 559 & 26.7 & 176 & 41.6 & 37.623 & 0.001 \\
\hline Irritability & 518 & 24.8 & 140 & 33.1 & 12.616 & $<0.001$ \\
\hline Response unknown & 151 & 7.2 & 31 & 7.3 & 0.006 & 0.938 \\
\hline
\end{tabular}

Notes: $\mathbf{A D}=$ Antidepressants. $\mathrm{RDC}=$ Research Diagnostic Criteria.

Specifically, our SLEEP+ group positively related with past mood elation, which in turn is traditionally associated with insomnia or decreased need for sleep (American Psychiatric Association, 2013; 2000). Our results, when confirmed prospectively using a longitudinal design, could support the hypothesis that insomnia and hypersomnia may and do occur within the same illness course (Kaplan and Williams, 2017).

Several other findings from the present study seem to support the association between hypersomnia and bipolar diathesis, such as younger age at the first psychiatric symptoms and younger age at first depressive episode in the SLEEP + group. These are among the most relevant clinical indicators of unrecognized bipolarity in depressed patients (Angst et al., 2012; 2010; Tondo et al., 2014). Also, the higher frequency of both DSM-5 and RDC mixed specifier during the index depressive episode in the SLEEP+ group points towards an association with bipolarity (Iwanami et al., 2015; Mclntyre et al., 2015; Solé et al., 2017; Takeshima and Oka, 2015). Yet, the DSM-5 specifier fails to consider the possibility of an increased duration of sleep as possible symptom of mixicity, potentially leaving aside patients that could very well fit into the group (Pacchiarotti et al., 2011; Popovic et al., 2016).

With respect to treatment regimens, SLEEP+ presented significantly higher frequencies of mood stabilizers and atypical antipsychotics use, coherently with the higher BD prevalence Also, SLEEP+ patients reported, in the past, higher rates of antidepressant use, resistance, associated (hypo)manic switches, and worsening of depression (with affective lability, aggressiveness, chronicity), all these factors being associated with bipolarity in our same sample (Barbuti et al., 2017; Mazzarini et al., 2018; Verdolini et al., 2017). This converges with past observations on the association between hypersomnia and worse response to AD treatment that call for specific therapeutic strategies (Kaplan and Williams, 2017; Verdolini et al., 2018).

From a prognostic standpoint, SLEEP+ group had a significant poorer outcome correlates expressed by higher rates of comorbidities, especially with bulimia, OCD, social phobia and GAD, higher rates of suicide ideation, compared to SLEEP- and in line with previous studies (Bernert et al., 2017a; 2017b; Michaels et al., 2017; ten Have et al., 2018; van Krugten et al., 2018). Hence, hypersomnia is a relevant target for early intervention strategies (Vieta et al., 2018b).

In our results, different significant findings in SLEEP + patients pointed at metabolic and weight-related features, such as higher rates of comorbid eating disorders (i.e. binge eating disorders, night eating and bulimia), and BMI from overweight to obese. This significance persisted after logistic regression, as bulimia and BMI above normal significantly contributed as unique factors to the likelihood of hypersomnia. These associations, together with the finding of a bipolar diathesis in the SLEEP + group, outline a possible shared susceptibility to BD and metabolic disturbances manifested as obesity/weight gain, in line with previous data (Boudebesse et al., 2015). For these reasons, we specifically studied the extreme phenotype of hypersomnia and overweight/obese (BMI > 25, above normal) patients. Indeed, this subgroup presented a clear overlap with the whole SLEEP+ population, presenting an even stronger 
Table 4 Comorbid-related characteristics and treatments of the included sample.

\begin{tabular}{|c|c|c|c|c|c|c|}
\hline \multirow[b]{2}{*}{ Variables (YES) } & \multicolumn{2}{|c|}{ Sleep- $(n=2091)$} & \multicolumn{2}{|c|}{ Sleep $+(n=423)$} & \multirow[b]{2}{*}{$x^{2}$} & \multirow[b]{2}{*}{$p$} \\
\hline & $n$ & $\%$ & $n$ & $\%$ & & \\
\hline \multicolumn{7}{|l|}{ Comorbidities } \\
\hline Panic disorder & 222 & 10.6 & 49 & 11.6 & 0.349 & 0.548 \\
\hline OCD & 87 & 4.2 & 32 & 7.6 & 9.072 & 0.002 \\
\hline Social phobia & 134 & 6.4 & 57 & 13.5 & 24.929 & $<0.001$ \\
\hline GAD & 358 & 17.2 & 98 & 23.2 & 8.667 & 0.003 \\
\hline Eating disorders & 124 & 6.0 & 57 & 13.7 & 30.9555 & $<0.001$ \\
\hline Binge eating syndrome & 40 & 1.9 & 25 & 6.0 & 22.721 & $<0.001$ \\
\hline Anorexia & 99 & 4.8 & 29 & 7.0 & 3.441 & 0.068 \\
\hline Bulimia & 20 & 1.0 & 25 & 6.1 & 49.939 & $<0.001$ \\
\hline Night eating syndrome & 46 & 2.2 & 23 & 5.5 & 14.099 & $<0.001$ \\
\hline ADHD & 45 & 2.2 & 12 & 2.9 & 0.776 & 0.378 \\
\hline Borderline personality & 136 & 6.5 & 27 & 6.4 & 0.009 & 1.000 \\
\hline \multicolumn{7}{|l|}{ Alcohol abuse } \\
\hline Use resulting in failure & 104 & 5.0 & 17 & 4.0 & 0.706 & 0.401 \\
\hline In hazardous situations & 54 & 2.6 & 11 & 2.6 & $<0.001$ & 0.985 \\
\hline Legal problems & 21 & 1.0 & 3 & 0.7 & 0.327 & 0.568 \\
\hline Continuous & 48 & 2.3 & 13 & 3.1 & 0.890 & 0.345 \\
\hline Never dependence & 1330 & 63.8 & 253 & 60.0 & 2.220 & 0.150 \\
\hline \multicolumn{7}{|l|}{ Substance abuse } \\
\hline Use resulting in failure & 33 & 1.6 & 4 & 0.9 & 0.975 & 0.504 \\
\hline In hazardous situations & 20 & 1.0 & 3 & 0.7 & 0.239 & 0.785 \\
\hline Legal problems & 6 & 0.3 & 3 & 0.7 & 1.755 & 0.185 \\
\hline Continuous & 43 & 2.1 & 8 & 1.9 & 0.047 & 1.000 \\
\hline Never dependence & 1326 & 63.6 & 262 & 62.2 & 0.281 & 0.596 \\
\hline \multicolumn{7}{|l|}{ Treatments } \\
\hline No treatment & 234 & 11.2 & 43 & 10.2 & 0.377 & 0.609 \\
\hline BZDs & 978 & 46.8 & 190 & 44.9 & 0.486 & 0.485 \\
\hline Other anxiolytics & 85 & 4.1 & 15 & 3.5 & 0.248 & 0.618 \\
\hline SSRIS & 942 & 45.1 & 190 & 44.9 & 0.003 & 0.960 \\
\hline SNRIs & 388 & 18.6 & 79 & 18.7 & 0.003 & 0.954 \\
\hline TCAs & 386 & 18.5 & 72 & 17.0 & 0.489 & 0.484 \\
\hline Other antidepressants & 216 & 10.3 & 55 & 13.0 & 2.613 & 0.106 \\
\hline Typical antipsychotics & 216 & 10.3 & 51 & 12,1 & 1.105 & 0.293 \\
\hline Atypical antipsychotics & 463 & 22.1 & 144 & 34.0 & 27.203 & $<0.001$ \\
\hline Mood stabilizers & 544 & 26.0 & 169 & 40.0 & 33.633 & $<0.001$ \\
\hline ECT & 39 & 1.9 & 6 & 1.4 & 0.399 & 0.527 \\
\hline
\end{tabular}

Notes: $\mathrm{OCD}=$ Obsessive-Compulsive Disorder; GAD = Generalized Anxiety Disorder; ADHD = Attention Deficit Hyperactivity Disorder; BZD = Benzodiazepine; SSRI Selective Serotonin Re-Uptake Inhibitor; SNRI = Serotonin and norepinephrine reuptake inhibitors; TCA = Tricyclic Antidepressant; ECT = Electro-Convulsive Treatment.

association with mixicity and BD-related clinical and prognostic features, such as the use of BD treatments, poor response to antidepressants and presence of affective lability.

Last, in our study, the cumulative effects of risk factors for obesity and hypersomnia outlined a significant role of medications such as atypical antipsychotics and moodstabilizers. The effect of these treatments on both increased sleep and appetite is well known (Yatham et al., 2018), even though in our study is not preponderant.

\section{Limitations}

Although this study tried to provide clinical and prognostic information on the associations between hypersomnia, obesity and $\mathrm{BD}$ on a large sample of MDE patients, several limitations can be highlighted. First, the cross-sectional design of both the primary study and this post-hoc analysis does not allow for causal inferences. Second, a confounding effect is the greater use of medications strongly related with weight-gain and sedation such as atypical antipsychotics and mood stabilizers, both in SLEEP+ and hypersomnia/overweight groups. Third, the sample of acutely depressed patients does not present an evaluation of euthymic phases, neither in unipolar, nor in BD patients. Moreover, we relied on the definition of sleep problems on the basis of the absence/presence of the symptom, but we did not assessed total sleep hours, daytime sleepiness or delay phase of sleep, that would have. Similarly, we did not employ specific sleep questionnaires or objective instrumental 
Table 5 Final variables in the stepwise backward logistic regression model.

\begin{tabular}{|c|c|c|c|c|c|c|c|c|}
\hline & \multirow[t]{2}{*}{ B } & \multirow[t]{2}{*}{ S.E. } & \multirow[t]{2}{*}{ Wald } & \multirow[t]{2}{*}{ df } & \multirow[t]{2}{*}{ Sig. } & \multirow[t]{2}{*}{$\operatorname{Exp}(B)$} & \multicolumn{2}{|c|}{ 95\% C.I.for EXP(B) } \\
\hline & & & & & & & Lower & Upper \\
\hline Overweight-obese BMI & 0.348 & 0.116 & 8.953 & 1 & 0.003 & 1.417 & 1.128 & 1.780 \\
\hline Tot days DEP/last year & 0.001 & 0.001 & 5.367 & 1 & 0.021 & 1.001 & 1.000 & 1.002 \\
\hline Age at 1 st DEP & -0.018 & 0.005 & 12.510 & 1 & 0.000 & 0.983 & 0.973 & 0.992 \\
\hline Lifetimes suicide attempts & 0.266 & 0.131 & 4.151 & 1 & 0.042 & 1.305 & 1.010 & 1.686 \\
\hline Current OCD & 0.426 & 0.230 & 3.433 & 1 & 0.064 & 1.531 & 0.976 & 2.403 \\
\hline Current social phobia & 0.572 & 0.184 & 9.641 & 1 & 0.002 & 1.772 & 1.235 & 2.543 \\
\hline Current bulimia & 1.437 & 0.330 & 19.013 & 1 & 0.000 & 4.210 & 2.206 & 8.033 \\
\hline Affective lability (past AD) & 0.316 & 0.129 & 6.056 & 1 & 0.014 & 1.372 & 1.067 & 1.766 \\
\hline Affective lability (current) & 0.311 & 0.128 & 5.940 & 1 & 0.015 & 1.365 & 1.063 & 1.752 \\
\hline Risky behaviors symptom & -1.133 & 0.264 & 18.423 & 1 & 0.000 & 0.322 & 0.192 & 0.540 \\
\hline Currently on AAP & 0.306 & 0.130 & 5.582 & 1 & 0.018 & 1.359 & 1.054 & 1.752 \\
\hline Currently on MS & 0.288 & 0.132 & 4.786 & 1 & 0.029 & 1.334 & 1.030 & 1.726 \\
\hline
\end{tabular}

Notes: C.I. = Confidence Intervals. AAP = Atypical Antipsychotics; AD = Antidepressants; BMI = Body-Mass Index; DEP = Depression; MS = Mood Stabilizers; OCD = Obsessive-Compulsive Disorder.

sleep measurements, such as actigraphy and polysomnography. Yet, the very definitions of insomnia and hypersomnia provide a univocal and objective, albeit clinical, esteem of increased and decreased sleep, commonly observed from the perspective of daily clinical practice.

\section{Conclusions}

The findings in the present post-hoc analysis outline the important of hypersomnia as a negative factor in a major depressive episode. Moreover, its strong link with bipolar diathesis calls for its potential discriminative validity in the differential diagnosis between unipolar and bipolar depression. Along with commonly used screeners for bipolarity, excessive duration of night sleep represents an effective, costless clinical feature to be taken into account in the diagnostic assessment of an acute depressive episode.

The co-occurrence of hypersomnia and overweight/obesity might represent a more extreme clinical phenotype of bipolarity complicated by treatment-related adverse effects. BD patients presenting hypersomnia and obese/overweight could benefit from an integrated approach aimed at reducing the impact of these risk factors through the improvement of dietary habits, physical activity, sleep hygiene, lifestyle behaviors, along with tolerable pharmacological treatments, in order to ameliorate their illness course and outcome.

\section{Role of funding source}

The sponsor of this study (Sanofi-Aventis) was involved in the study design, conduct, monitoring, and preparation of the final database, but not in the content of this report. All investigators recruited received fees from the sponsor in recognition of their participation in the study on a per patient basis. The Instituto de Salud Carlos III supported this work through a "Río Hortega" contract (CM17/00258) to NV. The Instituto de Salud Carlos III was not involved in the study design, conduct, monitoring, preparation of the final database or on the final data analysis of this report. The corresponding author had full access to all the data and had final responsibility for data analyses, preparation of the report, and the decision to submit for publication.

\section{Contributors}

All listed authors have contributed significantly to the manuscript and consent to their names on the manuscript.

\section{Conflicts of interest}

1. Prof. Angst has nothing to disclose.

2. Dr. Anmella-Diaz has nothing to disclose.

3. Dr. Azorin reports grants, personal fees and nonfinancial support from Sanofi-aventis, during the conduct of the study; personal fees and non-financial support from Janssen, personal fees and non-financial support from Lundbeck, personal fees and non-financial support from Roche, personal fees and non-financial support from Servier, personal fees and non-financial support from Takeda, outside the submitted work.

4. Dr. Barbuti has nothing to disclose.

5. Dr. Bowden has nothing to disclose.

6. Dr. Guiso has nothing to disclose.

7. Dr. Mosolov has nothing to disclose.

8. Dr. Murru has nothing to disclose.

9. Dr. Pacchiarotti has nothing to disclose.

10. Prof. Perugi has acted as consultant of Eli Lilly, Lundbeck, Angelini; received grant/research support from Lundbeck; is on the speaker/advisory board of SanofiAventis, Eli Lilly, Lundbeck, FB-Health, Angelini.

11. Dr. Popovic has nothing to disclose.

12. Dr. Samalin reports personal fees and non-financial support from Janssen, personal fees and non-financial support from Lundbeck, personal fees and non-financial support from Otsuka, personal fees and non-financial support from Takeda, personal fees and non-financial support from AstraZeneca, outside the submitted work;. 
13. Prof. Valdes has nothing to disclose.

14. Dr. Verdolini reports grants from Instituto de Salud Carlos III, "Río Hortega" contract (CM17/00258), during the conduct of the study.

15. Dr. Vieta reports grants from AB-Biotics, personal fees from Allergan, grants from Dainippon Sumitomo Pharma, grants and personal fees from Ferrer, personal fees from Geodon Richter, grants and personal fees from Janssen, grants and personal fees from Lundbeck, personal fees from Otsuka, personal fees from Sunovion, personal fees from Takeda, outside the submitted work.

16. Dr. Young reports grants from Janssen, personal fees from Janssen, personal fees from Lundbeck, personal fees from Livanova, personal fees from Sunovion, from null, outside the submitted work

\section{Acknowledgment}

The authors thank the support of the Spanish Ministry of Science, Innovation and Universities integrated into the Plan Nacional de I+D+I and co-financed by the ISCIIISubdirección General de Evaluación and the Fondo Europeo de Desarrollo Regional (FEDER); the CIBERSAM (Centro de Investigación Biomédica en Red de Salud Mental); the Secretaria d'Universitats i Recerca del Departament d'Economia i Coneixement (2017 SGR 1365) and the CERCA Programme / Generalitat de Catalunya.

\section{Supplementary material}

Supplementary material associated with this article can be found, in the online version, at doi:10.1016/j.euroneuro. 2019.02.011.

\section{References}

American Psychiatric Association, 2013. DSM-5: Diagnostic and Statistical Manual of Mental Disorders, fifth ed. APA, Washington DC.

American Psychiatric Association, 2000. DSM-IV-TR: Diagnostic and Statistical Manual of Mental Disorders, forth ed. APA, Washington DC doi:10.1001/jama.1994.03520100096046.

Angst, J., Adolfsson, R., Benazzi, F., Gamma, A., Hantouche, E., Meyer, T.D., Skeppar, P., Vieta, E., Scott, J., 2005. The HCL32: towards a self-assessment tool for hypomanic symptoms in outpatients. J. Affect. Disord. 88, 217-233. doi:10.1016/j.jad. 2005.05.011.

Angst, J., Azorin, J.-M., Bowden, C.L., Perugi, G., Vieta, E., Gamma, A., Young, A.H., 2011. Prevalence and characteristics of undiagnosed bipolar disorders in patients with a major depressive episode: the BRIDGE study. Arch. Gen. Psychiatry 68, 791-798. doi:10.1001/archgenpsychiatry.2011.87.

Angst, J., Cui, L., Swendsen, J., Rothen, S., Cravchik, A., Kessler, R.C., Merikangas, K.R., 2010. Major depressive disorder with subthreshold bipolarity in the National Comorbidity Survey Replication. Am. J. Psychiatry 167, 1194-1201. doi:10.1176/ appi.ajp.2010.09071011.

Angst, J., Gamma, A., Bowden, C.L., Azorin, J.M., Perugi, G., Vieta, E., Young, A.H., 2013. Evidence-based definitions of bipolar-I and bipolar-II disorders among 5,635 patients with major depressive episodes in the bridge study: validity and comorbidity. Eur. Arch. Psychiatry Clin. Neurosci. 263, 663-673. doi:10.1007/s00406-013-0393-4.
Angst, J., Gamma, A., Bowden, C.L., Azorin, J.M., Perugi, G., Vieta, E., Young, A.H., 2012. Diagnostic criteria for bipolarity based on an international sample of 5,635 patients with DSM-IV major depressive episodes. Eur. Arch. Psychiatry Clin. Neurosci. 262, 3-11. doi:10.1007/s00406-011-0228-0.

Asaad, T., Sabry, W., Rabie, M., El-Rassas, H., 2016. Polysomnographic characteristics of bipolar hypomanic patients: comparison with unipolar depressed patients. J. Affect. Disord. 191, 274-279. doi:10.1016/j.jad.2015.12.001.

Baglioni, C., Riemann, D., 2012. Is chronic insomnia a precursor to major depression? Epidemiological and biological findings. Curr. Psychiatry Rep. 14, 511-518. doi:10.1007/s11920-012-0308-5.

Bao, Y.-P., Han, Y., Ma, J., Wang, R.-J., Shi, L., Wang, T.-Y., He, J., Yue, J.-L., Shi, J., Tang, X.-D., Lu, L., 2017. Cooccurrence and bidirectional prediction of sleep disturbances and depression in older adults: meta-analysis and systematic review. Neurosci. Biobehav. Rev. 75, 257-273. doi:10.1016/j.neubiorev.2017.01. 032.

Barbuti, M., Pacchiarotti, I., Vieta, E., Azorin, J.-M., Angst, J., Bowden, C.L., Mosolov, S., Young, A.H., Perugi, G.BRIDGE-II-Mix Study Group, 2017. Antidepressant-induced hypomania/mania in patients with major depression: evidence from the BRIDGEII-MIX study. J. Affect. Disord. 219, 187-192. doi:10.1016/j.jad. 2017.05.035.

Bernert, R.A., Hom, M.A., Iwata, N.G., Joiner, T.E., 2017a. Objectively assessed sleep variability as an acute warning sign of suicidal ideation in a longitudinal evaluation of young adults at high suicide risk. J. Clin. Psychiatry 78, e678-e687. doi:10.4088/JCP. $16 \mathrm{~m} 11193$.

Bernert, R.A., Luckenbaugh, D.A., Duncan, W.C., Iwata, N.G., Ballard, E.D., Zarate, C.A., 2017b. Sleep architecture parameters as a putative biomarker of suicidal ideation in treatmentresistant depression. J. Affect. Disord. 208, 309-315. doi:10. 1016/j.jad.2016.08.050.

Boudebesse, C., Geoffroy, P.-A., Henry, C., Germain, A., Scott, J., Lajnef, M., Leboyer, M., Bellivier, F., Etain, B., 2015. Links between sleep and body mass index in bipolar disorders: an exploratory study. Eur. Psychiatry 30, 89-93. doi:10.1016/j.eurpsy. 2014.04.006.

Bradley, A.J., Webb-Mitchell, R., Hazu, A., Slater, N., Middleton, B., Gallagher, P., McAllister-Williams, H., Anderson, K.N., 2017. Sleep and circadian rhythm disturbance in bipolar disorder. Psychol. Med. 47, 1678-1689. doi:10.1017/ S0033291717000186.

Bromberger, J.T., Kravitz, H.M., Youk, A., Schott, L.L., Joffe, H., 2016. Patterns of depressive disorders across 13 years and their determinants among midlife women: SWAN mental health study. J. Affect. Disord. 206, 31-40. doi:10.1016/j.jad.2016.07.005.

Chou, K.-L., Yu, K.-M., 2013. Atypical depressive symptoms and obesity in a national sample of older adults with major depressive disorder. Depress. Anxiety 30, 574-579. doi:10.1002/ da. 22098.

Craig, T.J., Bromet, E.J., Fennig, S., Tanenberg-Karant, M., Lavelle, J., Galambos, N., 2000. Is there an association between duration of untreated psychosis and 24-month clinical outcome in a first-admission series? Am. J. Psychiatry 157, 6066. doi:10.1176/ajp.157.1.60.

de Wit, L., Luppino, F., van Straten, A., Penninx, B., Zitman, F., Cuijpers, P., 2010. Depression and obesity: a meta-analysis of community-based studies. Psychiatry Res. 178, 230-235. doi:10. 1016/j.psychres.2009.04.015.

Endicott, J., Spitzer, R.L., Fleiss, J.L., Cohen, J., 1976. The global assessment scale. A procedure for measuring overall severity of psychiatric disturbance. Arch. Gen. Psychiatry 33, 766771.

Fagiolini, A., Kupfer, D.J., Rucci, P., Scott, J.A., Novick, D.M., Frank, E., 2004. Suicide attempts and ideation in patients with bipolar I disorder. J. Clin. Psychiatry 65, 509-514. 
Forty, L., Smith, D., Jones, L., Jones, I., Caesar, S., Cooper, C., Fraser, C., Gordon-Smith, K., Hyde, S., Farmer, A., McGuffin, P., Craddock, N., 2008. Clinical differences between bipolar and unipolar depression. Br. J. Psychiatry 192, 388-389. doi:10.1192/bjp.bp.107.045294.

Gershon, A., Do, D., Satyanarayana, S., Shah, S., Yuen, L.D., Hooshmand, F., Miller, S., Wang, P.W., Ketter, T.A., 2017. Abnormal sleep duration associated with hastened depressive recurrence in bipolar disorder. J. Affect. Disord. 218, 374-379. doi:10.1016/j.jad.2017.05.015.

Iwanami, T., Maeshima, H., Baba, H., Satomura, E., Namekawa, Y., Shimano, T., Suzuki, T., Arai, H., 2015. Psychomotor agitation in major depressive disorder is a predictive factor of moodswitching. J. Affect. Disord. 170, 185-189. doi:10.1016/j.jad. 2014.09.001.

Kapczinski, F., Frey, B.N., Vieta, E., 2011. Sleep and circadian rhythm disturbances in bipolar disorder: an urgent need for objective assessment and systematic follow-up. J. Clin. Psychiatry 72, 724. doi: $10.4088 /$ JCP. 11106850.

Kaplan, K.A., Williams, R., 2017. Hypersomnia: an overlooked, but not overestimated, sleep disturbance in bipolar disorder. Evid. Based. Ment. Health 20, 59. doi:10.1136/eb-2016-102433.

Lasserre, A.M., Glaus, J., Vandeleur, C.L., Marques-Vidal, P., Vaucher, J., Bastardot, F., Waeber, G., Vollenweider, P., Preisig, M. , 2014. Depression with atypical features and increase in obesity, body mass index, waist circumference, and fat mass: a prospective, population-based study. JAMA Psychiatry 71, 880888. doi:10.1001/jamapsychiatry.2014.411.

Littlewood, D.L., Kyle, S.D., Carter, L.-A., Peters, S., Pratt, D., Gooding, P., 2018. Short sleep duration and poor sleep quality predict next-day suicidal ideation: an ecological momentary assessment study. Psychol. Med. 1-9. doi:10.1017/ S0033291718001009.

Liu, C.S., Carvalho, A.F., Mansur, R.B., McIntyre, R.S., 2013. Obesity and bipolar disorder: synergistic neurotoxic effects? Adv. Ther. 30, 987-1006. doi:10.1007/s12325-013-0067-7.

Łojko, D., Buzuk, G., Owecki, M., Ruchała, M., Rybakowski, J.K., 2015. Atypical features in depression: association with obesity and bipolar disorder. J. Affect. Disord. 185, 76-80. doi:10.1016/ j.jad.2015.06.020.

Luppino, F.S., de Wit, L.M., Bouvy, P.F., Stijnen, T., Cuijpers, P., Penninx, B.W.J.H., Zitman, F.G., 2010. Overweight, obesity, and depression. Arch. Gen. Psychiatry 67, 220. doi:10.1001/ archgenpsychiatry.2010.2.

Mazzarini, L., Kotzalidis, G.D., Piacentino, D., Rizzato, S., Angst, J., Azorin, J.-M., Bowden, C.L., Mosolov, S., Young, A.H., Vieta, E., Girardi, P., Perugi, G.BRIDGE-II-Mix Study Group, 2018. Is recurrence in major depressive disorder related to bipolarity and mixed features? Results from the BRIDGE-II-Mix study. J. Affect. Disord 229, 164-170. doi:10.1016/j.jad.2017.12.062.

McElroy, S.L., Crow, S., Biernacka, J.M., Winham, S., Geske, J., Cuellar Barboza, A.B., Prieto, M.L., Chauhan, M., Seymour, L.R., Mori, N., Frye, M.A., 2013. Clinical phenotype of bipolar disorder with comorbid binge eating disorder. J. Affect. Disord. 150, 981-986. doi:10.1016/j.jad.2013.05.024.

McElroy, S.L., Frye, M.A., Hellemann, G., Altshuler, L., Leverich, G.S., Suppes, T., Keck, P.E., Nolen, W.A., Kupka, R., Post, R.M., 2011. Prevalence and correlates of eating disorders in 875 patients with bipolar disorder. J. Affect. Disord. 128, 191198. doi:10.1016/j.jad.2010.06.037.

McElroy, S.L., Keck, P.E., 2014. Metabolic syndrome in bipolar disorder. J. Clin. Psychiatry 75, 46-61. doi:10.4088/JCP.13r08634.

McElroy, S.L., Winham, S.J., Cuellar-Barboza, A.B., Colby, C.L., Ho, A.M.-C., Sicotte, H., Larrabee, B.R., Crow, S., Frye, M.A., Biernacka, J.M., 2018. Bipolar disorder with binge eating behavior: a genome-wide association study implicates PRR5-ARHGAP8. Trans. Psychiatry 8, 40. doi:10.1038/s41398-017-0085-3.
Mclntyre, R.S., Soczynska, J.K., Cha, D.S., Woldeyohannes, H.O., Dale, R.S., Alsuwaidan, M.T., Gallaugher, L.A., Mansur, R.B., Muzina, D.J., Carvalho, A., Kennedy, S.H., 2015. The prevalence and illness characteristics of DSM-5-defined "mixed feature specifier" in adults with major depressive disorder and bipolar disorder: results from the International Mood Disorders Collaborative Project. J. Affect. Disord. 172, 259-264. doi:10. 1016/j.jad.2014.09.026.

Michaels, M.S., Balthrop, T., Nadorff, M.R., Joiner, T.E., 2017. Total sleep time as a predictor of suicidal behaviour. J. Sleep Res. 26, 732-738. doi:10.1111/jsr.12563.

Mosolov, S.N., 1996. Sleep parameters in bipolar rapid cycling patients. Eur. Psychiatry 11, 351s. doi:10.1016/0924-9338(96) 89110-3.

Pacchiarotti, I., Mazzarini, L., Kotzalidis, G.D., Valentí, M., Nivoli, A.M.A., Sani, G., Torrent, C., Murru, A., SanchezMoreno, J., Patrizi, B., Girardi, P., Vieta, E., Colom, F., 2011. Mania and depression. Mixed, not stirred. J. Affect. Disord. 133, 105-113.

Perugi, G., Angst, J., Azorin, J.-M., Bowden, C.L., Caciagli, A., Mosolov, S., Vieta, E., Young, A.H.BRIDGE-II-Mix Study Group, 2016. Relationships between mixed features and borderline personality disorder in 2811 patients with major depressive episode. Acta Psychiatr. Scand. 133, 133-143. doi:10.1111/acps. 12457.

Perugi, G., Angst, J., Azorin, J.-M., Bowden, C.L., Mosolov, S., Reis, J., Vieta, E., Young, A.H.BRIDGE-II-Mix Study Group, 2015. Mixed features in patients with a major depressive episode. J. Clin. Psychiatry 76, e351-e358. doi:10.4088/JCP.14m09092.

Petri, E., Bacci, O., Barbuti, M., Pacchiarotti, I., Azorin, J.-M., Angst, J., Bowden, C.L., Mosolov, S., Vieta, E., Young, A.H., Perugi, G.BRIDGE-II-Mix Study Group, 2017. Obesity in patients with major depression is related to bipolarity and mixed features: evidence from the BRIDGE-II-Mix study. Bipolar Disord. 19, 458-464. doi:10.1111/bdi.12519.

Popovic, D., Torrent, C., Vieta, E., Azorin, J.M., Angst, J., Mosolov, S., Bowden, C.L., Young, A., 2016. Hypomanic symptoms in mixed depression - is DSM-5 wrong? Evidence from the BRIDGE-II-MIX study. Eur. Psychiatry 33, S131. doi:10.1016/J. EURPSY.2016.01.162.

Popovic, D., Vieta, E., Azorin, J.-M., Angst, J., Bowden, C.L., Mosolov, S., Young, A.H., Perugi, G., 2015. Suicide attempts in major depressive episode: evidence from the BRIDGE-II-Mix study. Bipolar Disord 17, 795-803. doi:10.1111/bdi.12338.

Rosa, A.R., Comes, M., Torrent, C., Solè, B., Reinares, M., Pachiarotti, I., Salamero, M., Kapczinski, F., Colom, F., Vieta, E., 2013. Biological rhythm disturbance in remitted bipolar patients. Int. J. Bipolar Disord. 1, 6. doi:10.1186/2194-7511-1-6.

Sakurai, H., Suzuki, T., Yoshimura, K., Mimura, M., Uchida, H., 2017. Predicting relapse with individual residual symptoms in major depressive disorder: a reanalysis of the STAR*D data. Psychopharmacology (Berl) 234, 2453-2461. doi:10.1007/ s00213-017-4634-5.

Samalin, L., Boyer, L., Murru, A., Pacchiarotti, I., Reinares, M., Bonnin, C.M., Torrent, C., Verdolini, N., Pancheri, C., de Chazeron, I., Boucekine, M., Geoffroy, P.-A., Bellivier, F., Llorca, P.M., Vieta, E., 2017. Residual depressive symptoms, sleep disturbance and perceived cognitive impairment as determinants of functioning in patients with bipolar disorder. J. Affect. Disord. 210, 280-286. doi:10.1016/j.jad.2016.12.054.

Simon, G.E., Von Korff, M., Saunders, K., Miglioretti, D.L., Crane, P.K., van Belle, G., Kessler, R.C., 2006. Association between obesity and psychiatric disorders in the US adult population. Arch. Gen. Psychiatry 63, 824. doi:10.1001/archpsyc.63.7. 824.

Solé, E., Garriga, M., Valentí, M., Vieta, E., 2017. Mixed features in bipolar disorder. CNS Spectr. 22, 134-140. doi:10.1017/ S1092852916000869. 
Steinan, M., Morken, G., Lagerberg, T.V., Melle, I., Andreassen, O.A., Vaaler, A.E., Scott, J., 2016a. Delayed sleep phase: an important circadian subtype of sleep disturbance in bipolar disorders. J. Affect. Disord. 191, 156-163. doi:10.1016/ j.jad.2015.11.025.

Steinan, M.K., Scott, J., Lagerberg, T.V., Melle, I., Andreassen, O.A., Vaaler, A.E., Morken, G., 2016b. Sleep problems in bipolar disorders: more than just insomnia. Acta Psychiatr. Scand. 133, 368-377. doi:10.1111/acps. 12523.

Strejilevich, S.A., Martino, D.J., Murru, A., Teitelbaum, J., Fassi, G., Marengo, E., Igoa, A., Colom, F., 2013. Mood instability and functional recovery in bipolar disorders. Acta Psychiatr. Scand. 128, 194-202. doi:10.1111/acps.12065.

Takaesu, Y., Inoue, Y., Ono, K., Murakoshi, A., Futenma, K., Komada, Y., Inoue, T., 2017. Circadian rhythm sleep-wake disorders as predictors for bipolar disorder in patients with remitted mood disorders. J. Affect. Disord. 220, 57-61. doi:10.1016/j. jad.2017.05.041.

Takeshima, M., Oka, T., 2015. DSM-5-defined “mixed features" and Benazzi's mixed depression: which is practically useful to discriminate bipolar disorder from unipolar depression in patients with depression? Psychiatry Clin. Neurosci. 69, 109-116. doi:10.1111/pcn.12213.

ten Have, M., de Graaf, R., van Dorsselaer, S., Tuithof, M., Kleinjan, M., Penninx, B.W.J.H., 2018. Recurrence and chronicity of major depressive disorder and their risk indicators in a population cohort. Acta Psychiatr. Scand. doi:10.1111/acps.12874.

Thase, M.E., 2007. Recognition and diagnosis of atypical depression. J. Clin. Psychiatry 68 (8), 11-16 Suppl.

Tondo, L., Visioli, C., Preti, A., Baldessarini, R.J., 2014. Bipolar disorders following initial depression: modeling predictive clinical factors. J. Affect. Disord. 167, 44-49. doi:10.1016/j.jad.2014. 05.043.

van Krugten, F.C.W., Goorden, M., van Balkom, A.J.L.M., Spijker, J., Brouwer, W.B.F., Hakkaart-van Roijen, L.Decision Tool Unipolar Depression Consortium, 2018. Indicators to facilitate the early identification of patients with major depressive disorder in need of highly specialized care: a concept mapping study. Depress. Anxiety 35, 346-352. doi:10.1002/da.22741.
Verdolini, N., Hidalgo-Mazzei, D., Murru, A., Pacchiarotti, I., Samalin, L., Young, A.H., Vieta, E., Carvalho, A.F., 2018. Mixed states in bipolar and major depressive disorders: systematic review and quality appraisal of guidelines. Acta Psychiatr. Scand. doi:10.1111/acps.12896.

Verdolini, N., Perugi, G., Samalin, L., Murru, A., Angst, J., Azorin, J.-M., Bowden, C.L., Mosolov, S., Young, A.H., Barbuti, M., Guiso, G., Popovic, D., Vieta, E., Pacchiarotti, I.BRIDGE-II-Mix Study Group, 2017. Aggressiveness in depression: a neglected symptom possibly associated with bipolarity and mixed features. Acta Psychiatr. Scand. 136, 362-372. doi:10.1111/acps.12777.

Vieta, E., Berk, M., Schulze, T.G., Carvalho, A.F., Suppes, T., Calabrese, J.R., Gao, K., Miskowiak, K.W., Grande, I., 2018a. Bipolar disorders. Nat. Rev. Dis. Prim. 4, 18008. doi:10.1038/nrdp. 2018.8.

Vieta, E., Salagre, E., Grande, I., Carvalho, A.F., Fernandes, B.S., Berk, M., Birmaher, B., Tohen, M., Suppes, T., 2018b. Early Intervention in Bipolar Disorder. Am. J. Psychiatry 175, 411-426. doi:10.1176/appi.ajp.2017.17090972.

Yatham, L.N., Kennedy, S.H., Parikh, S.V, Schaffer, A., Bond, D.J., Frey, B.N., Sharma, V., Goldstein, B.I., Rej, S., Beaulieu, S., Alda, M., MacQueen, G., Milev, R.V, Ravindran, A., O’Donovan, C., McIntosh, D., Lam, R.W., Vazquez, G., Kapczinski, F., McIntyre, R.S., Kozicky, J., Kanba, S., Lafer, B., Suppes, T., Calabrese, J.R., Vieta, E., Malhi, G., Post, R.M., Berk, M., 2018. Canadian Network for Mood and Anxiety Treatments (CANMAT) and International Society for Bipolar Disorders (ISBD) 2018 guidelines for the management of patients with bipolar disorder. Bipolar Disord. 20, 97-170. doi:10.1111/bdi.12609.

Yim, C.Y., Soczynska, J.K., Kennedy, S.H., Woldeyohannes, H.O., Brietzke, E., Mclntyre, R.S., 2012. The effect of overweight/obesity on cognitive function in euthymic individuals with bipolar disorder. Eur. Psychiatry 27, 223-228. doi:10.1016/ j.eurpsy.2011.02.004. 